\title{
MENSURAÇÃO DA TEMPERATURA DO SOLO SOLARIZADO E NÃO SOLARIZADO NA REGIÃO DE TANGARÁ DA SERRA - MT
}

\author{
Michael Douglas Biava Silvestri ${ }^{1}$, Leandro Rafael Fachi², Priscila da Silva Salmazo ${ }^{3}$, \\ Debora Sarana Ortolan Arantes ${ }^{3}$, Willian Marques Duarte ${ }^{4}$ \\ ${ }^{1}$ Eng. Agrônomo pela Universidade do Estado de Mato Grosso UNEMAT, Campus \\ de Tangará da Serra, MT-Brasil \\ ${ }^{2}$ Mestre, Pós-graduando em Biotecnologia e Biodiversidade pela Universidade \\ Federal do Mato Grosso UFMT, Campus de Cuiabá, MT-Brasil \\ (leandrofachi@hotmail.com) \\ ${ }^{3}$ Graduandas em Agronomia pela Universidade do Estado de Mato Grosso \\ UNEMAT, Campus de Tangará da Serra, MT-Brasil. \\ ${ }^{4}$ Eng. Agrônomo pela Universidade do Estado de Mato Grosso UNEMAT.
}

Recebido em: 22/09/2018 - Aprovado em: 23/11/2018 - Publicado em: 03/12/2018 DOI: 10.18677/EnciBio_2018B58

\begin{abstract}
RESUMO
A solarização é uma técnica de tratamento térmico que foi desenvolvida no Oriente Médio na década de 70 , ao qual era utilizado para desinfestar solos e substratos. A técnica se destaca pela eficiência, baixo custo e também por não agredir o meio ambiente. No Brasil essa técnica é pouco conhecida, o método é recomendado especialmente para culturas de ciclo curto e sistema radicular pouco profundo, como as hortaliças. O objetivo deste trabalho foi avaliar a temperatura do solo em diferentes profundidades e períodos com e sem cobertura do solo na região de Tangará da Serra - MT. O trabalho foi desenvolvido no campo experimental da Universidade do Estado de Mato Grosso (UNEMAT) campus de Tangará da Serra MT. O delineamento utilizado foi em blocos ao acaso (DBC), sendo um bifatorial composto pelos fatores profundidade do sensor $(2,7 \mathrm{~cm}, 7,3 \mathrm{~cm}, 19,7 \mathrm{~cm}$ e $53,1 \mathrm{~cm})$ e manejo do solo (com cobertura e sem cobertura plástica), com observações diárias. As avaliações foram realizadas no decorrer de oito dias após a instalação, e foram feitas através do termômetro termistor e um datalogger. Conclui-se que a temperatura do solo apresenta maior amplitude térmica em camadas superficiais e a medida que se aumenta a profundidade do solo a temperatura tende a diminuir.
\end{abstract}

PALAVRAS-CHAVE: amplitude térmica, manejo, profundidade.

\section{MEASUREMENT SOLARIZED SOIL SOLARIZED TEMPERATURE AND NOT IN THE REGION TANGARÁ DA SERRA - MT}

\begin{abstract}
Solarization is a heat treatment technique that was developed in the Middle East in the 1970s, to which it was used to disinfect soils and substrates. The technique stands out for efficiency, low cost and also for not attacking the environment. In Brazil this technique is little known, the method is recommended especially for cultures of short cycle and shallow root system, as the vegetables. The objective of this work was to evaluate soil temperature at different depths and periods with and without soil ENCICLOPÉDIA BIOSFERA, Centro Científico Conhecer - Goiânia, v.15 n.28; p. 667 2018
\end{abstract}


cover in the Tangará da Serra - MT region. The work was developed in the experimental field of the State University of Mato Grosso (UNEMAT) campus of Tangará da Serra - MT. The design was a randomized complete block design (DBC), consisting of depth sensor $(2.7 \mathrm{~cm}, 7.3 \mathrm{~cm}, 19.7 \mathrm{~cm}$ and $53.1 \mathrm{~cm})$ and soil without plastic cover), with daily observations. The evaluations were carried out over the course of eight days after installation and were done through thermistor thermometer and a datalogger. It is concluded that the temperature of the soil presents a greater thermal amplitude in superficial layers and as the soil depth increases the temperature tends to decrease.

KEYWORDS: thermal amplitude, handling, depth.

\section{INTRODUÇÃO}

A solarização é uma técnica de tratamento térmico que foi desenvolvida no Oriente Médio na década de 1970, ao qual era utilizada para a desinfestar solos e substratos antes do plantio (BARROS et al., 2004). Nesta técnica, a cobertura com polietileno transparente deve ser executada com o solo úmido em estações quentes do ano, antes de ser realizado o plantio da cultura na área (ROCHA; CARNEIRO, 2016).

Tal método é recomendado especialmente para culturas de ciclo curto e sistema radicular pouco profundo, como a maioria das hortaliças, auxiliando nos custos com mãos-de-obra no local, porém também pode ser utilizado em culturas perenes (AIMI, 2013).

A técnica de solarização se destaca pela eficiência, baixo custo, fácil instalação e por não agredir o meio ambiente, visto que utilizada energia proveniente da natureza e não faz uso de produtos químicos no solo (SANTOS et al., 2014). Esse processo fundamenta-se no princípio de que a radiação solar atravessa o filme plástico, converte-se em calor através da umidade presente no solo e consequente eleva a sua temperatura, podendo atingir valores superiores a $50^{\circ} \mathrm{C}$ (EMBRAPA, 2014).

Temperaturas elevadas inativam alguns patógenos e plantas daninhas do solo, além disso não erradicam microrganismos considerados benéficos, pois estes são mais tolerantes à altas temperaturas, o que otimiza o efeito dessa técnica por dificultarem a reinfestação do solo (ROCHA; CARNEIRO, 2016).

Países como Israel, Japão, Espanha, Itália e Grécia adotam a solarização devido às vantagens e benefícios que proporcionam para o solo (KUVA et al., 1995). Dentre as principais vantagens podemos citar o controle de diversos patógenos e o controle de plantas daninhas, redução da perda de água por evaporação do solo, facilidade na colheita e comercialização de um produto mais limpo (FACTOR et al., 2009).

A solarização do solo vem sendo empregada no controle de plantas daninhas, grande problema enfrentado pela agricultura orgânica. As perdas de produtividades, ocasionadas pela competição com as plantas cultivadas por água, luz e nutrientes, ultrapassam as perdas causadas pelo ataque pragas em qualquer cultura (ABOUZIENA; HAGGAG, 2016). Devido à preocupação da população com a produção de alimentos e questões ambientais em relação ao uso de defensivos químicos para o controle de plantas daninhas, procuram-se outras alternativas de controle que sejam eficientes e não tragam consequências ao meio ambiente (PUHL, 2013).

Com isso, estudos mais detalhados sobre a técnica de solarização em culturas tornam-se importantes para conhecimento dos agricultores que venham a 
se interessar no uso da mesma. Na região de Tangará da Serra, MT, o uso de cobertura plástica de solo ainda é reduzido, sendo utilizada com mais frequência em hortaliças. Assim, o objetivo deste trabalho foi avaliar a temperatura do solo em diferentes profundidades e períodos com ou sem cobertura plástica sobre o solo.

\section{MATERIAL E MÉTODOS}

O presente trabalho foi desenvolvido no campo experimental da Universidade do Estado de Mato Grosso (UNEMAT) - Campus Universitário de Tangará da Serra MT, localizado geograficamente a 14³9'00" de latitude Sul e $57^{\circ} 25^{\prime} 00^{\prime \prime}$ de longitude Oeste, com altitude de 440 metros.

O clima da região é o tropical chuvoso. Os valores de temperatura variam de 18 a $38^{\circ} \mathrm{C}$, com média de $25^{\circ} \mathrm{C}$ e precipitação média de $1.800 \mathrm{~mm}$ anuais sob altitude de $440 \mathrm{~m}$ (FENNER et al., 2017). As chuvas se concentram principalmente nos meses de outubro a março. Entre os meses de abril e setembro se destaca como estação seca. O solo é do tipo Latossolo Vermelho, de textura muito argilosa (EMBRAPA, 2006).

O delineamento utilizado foi o de blocos ao acaso, sendo um fatorial composto por dois fatores: profundidade do sensor $(2,7 ; 7,3 ; 19,7$ e $53,1 \mathrm{~cm})$ e manejo do solo (com cobertura e sem cobertura). A cada hora foram feitas avaliações em quatro níveis de profundidade com três repetições. No experimento, os canteiros possuíam medidas de $3 \mathrm{~m} \times 3 \mathrm{~m}$. No tratamento com cobertura plástica foi utilizado plástico transparente de 100 micras; nos dois tratamentos foi realizada a irrigação com tubo gotejador todos os dias.

As avaliações foram realizadas no decorrer de oito dias (29/09 a 06/10/2015), através do termômetro termistor. O sistema de mensuração é composto por um sensor termistor A 109, projetado especialmente para dataloggers, que consiste em uma sonda robusta que mede com precisão temperatura do ar, solo ou água de $50^{\circ} \mathrm{C} \mathrm{a}+70^{\circ} \mathrm{C}$. O termistor transforma o sinal gerado no sensor em sinal digital que é armazenado no aquisitor de dados, sendo este configurado para medir a temperatura a cada 60 minutos e armazenar os dados no datalloger.

Os dados obtidos foram submetidos à análise de variância segundo o delineamento de blocos casualizados (DBC) e foram colocados numa planilha de Microsoft Excel, onde foram feitas figuras que explicam melhores os resultados deste trabalho.

\section{RESULTADOS E DISCUSSÃO}

As diferenças de amplitude térmica diária do solo sem cobertura (não solarizado) para o solo com cobertura plástica (solarizado) são representadas na Figura 1. Nota-se que amplitudes térmicas diárias mais altas foram observadas na profundidade de $2,7 \mathrm{~cm}$ em ambos os sistemas de cobertura. Foi verificado que a temperatura máxima atingida estava em $21^{\circ} \mathrm{C}$ e mínima de $10^{\circ} \mathrm{C}$ no sistema solarizado, enquanto que no sistema não solarizado encontravam-se entre 20 a $6^{\circ} \mathrm{C}$, respectivamente.

Com o aumento da profundidade do solo, percebe-se que houve uma diminuição da amplitude térmica diária, sendo verificado as menores variações na profundidade de $53,1 \mathrm{~cm}\left(0\right.$ a $\left.0,8^{\circ} \mathrm{C}\right)$ no sistema solarizado e uma variação de 0,1 a $0,5^{\circ} \mathrm{C}$ para o sistema não solarizado. 


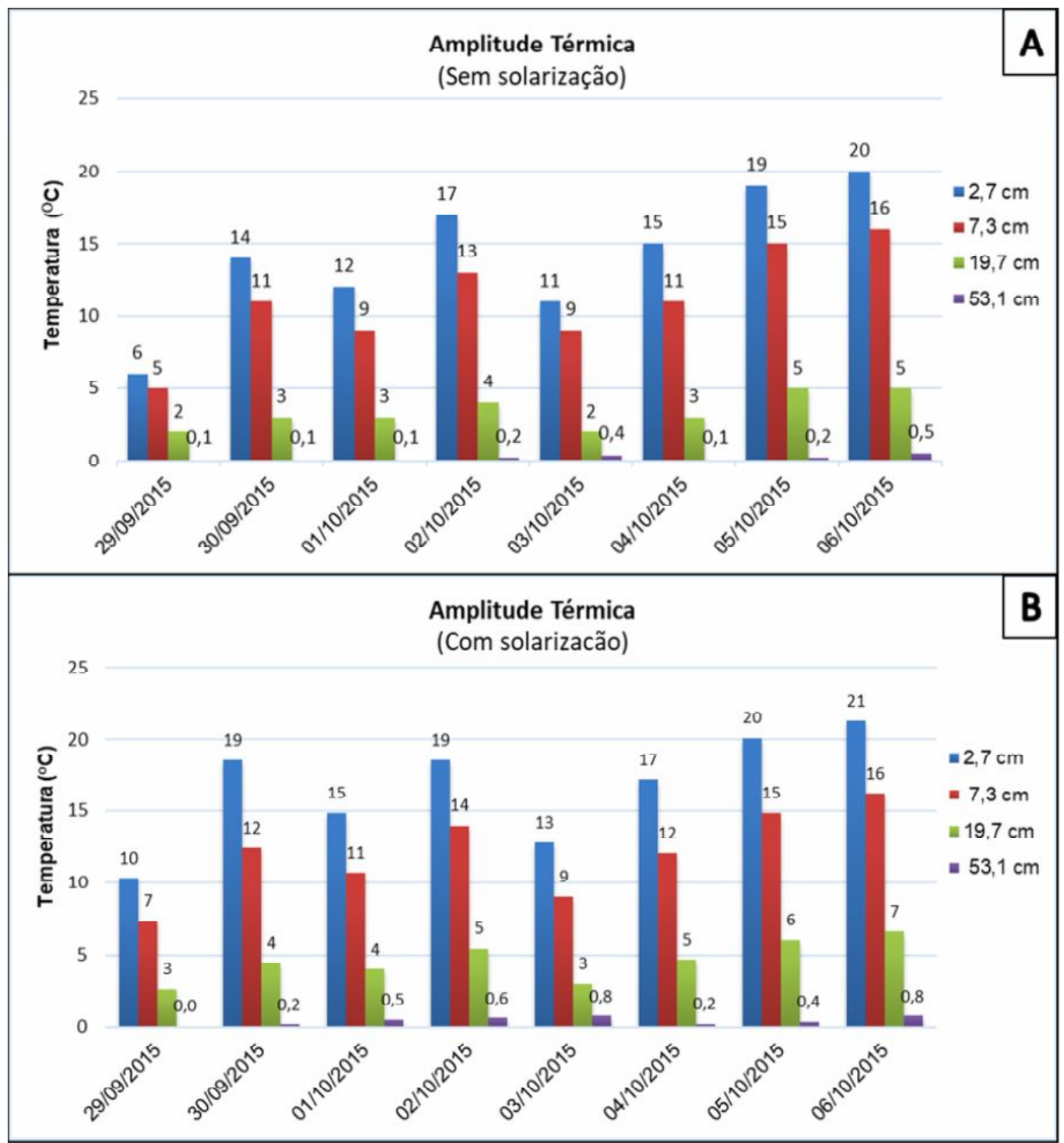

FIGURA 1 - Amplitude térmica diária do solo em profundidades de 2,7, 7,3, 19,7 e $53,1 \mathrm{~cm}$, em sistema não solarizado $(A)$ e em solarizado (B).

Resultados similares foram vistos por Diniz et al. (2014), avaliando características térmicas do solo, nas profundidades de 10, 20 e $50 \mathrm{~cm}$, verificaram que as maiores amplitudes térmicas diárias se situam mais próximas da superfície, devido sua propensão de receber e perder calor cotidianamente.

Os dados de temperatura média do sistema solarizado foram apurados por 24 horas no decorrer do dia 06 de outubro de 2015 e estão descritos na Figura 2. Durante a madrugada observou-se baixas temperaturas e a partir das 7:00 horas a temperatura aumenta, percebendo-se que houve aquecimento nas camadas superficiais. A profundidade de $2,7 \mathrm{~cm}$ teve uma variação de 35 a $54^{\circ} \mathrm{C}$. Em profundidades maiores a temperatura apresentou menor amplitude térmica. Nota-se que nas profundidades de $7,3 \mathrm{~cm}$ a temperatura atingiu valores mais altos entre 14:00 e 17:00 horas. 


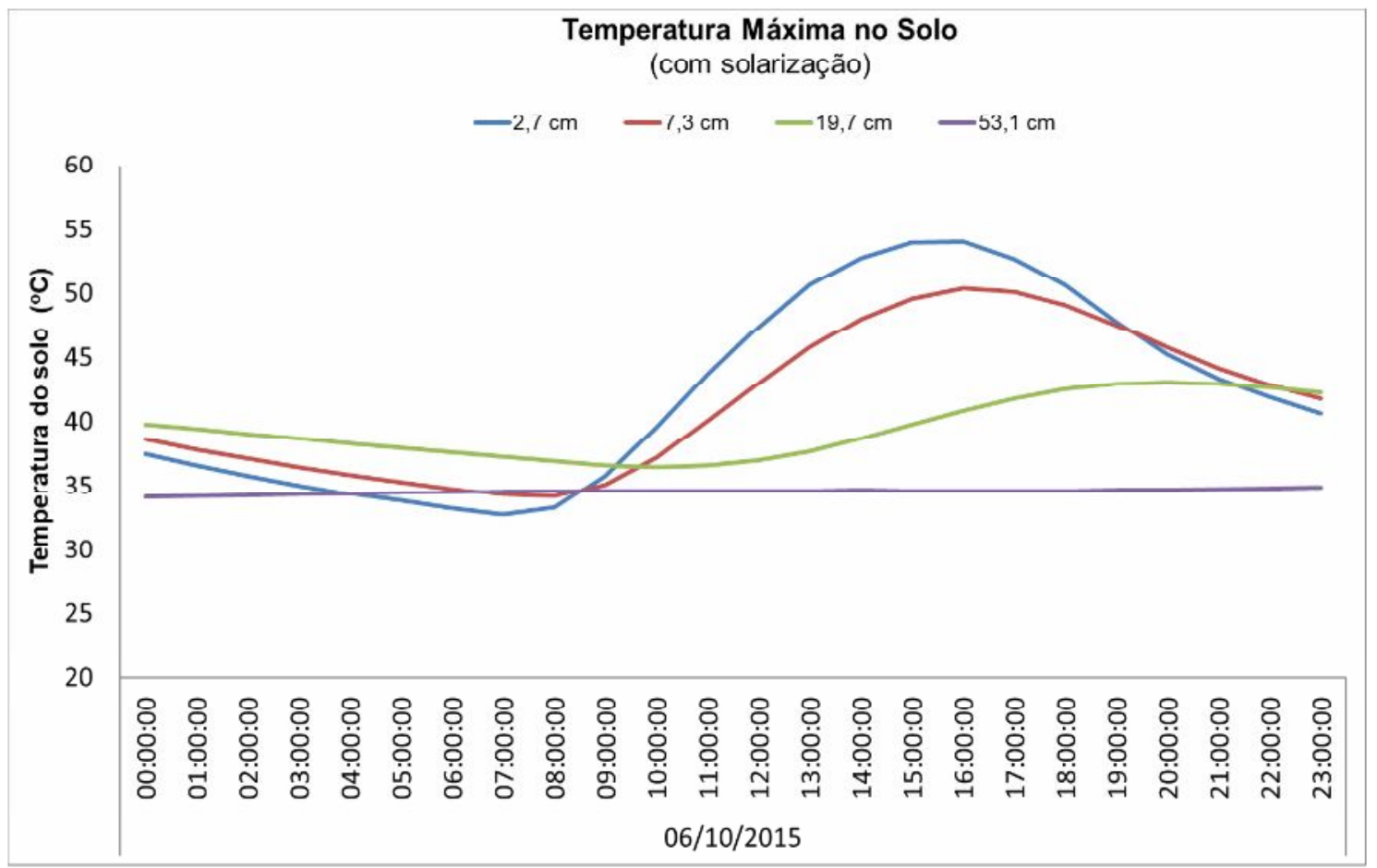

FIGURA 2 - Temperatura média do solo com solarização no dia 06 de outubro de 2015.

O comportamento do sistema não solarizado, são apresentados na Figura 3. A temperatura do solo atingiu sua máxima de $45^{\circ} \mathrm{C}$ as 15:00 horas, na profundidade de $2,7 \mathrm{~cm}$. Observou-se que na mesma profundidade a temperatura variou entre 45 e $54^{\circ} \mathrm{C}$, no sistema não solarizado e solarizado, respectivamente. Isso deixa evidente que a utilização de polietileno transparente proporciona valores mais elevados de temperatura do solo na camada superficial.

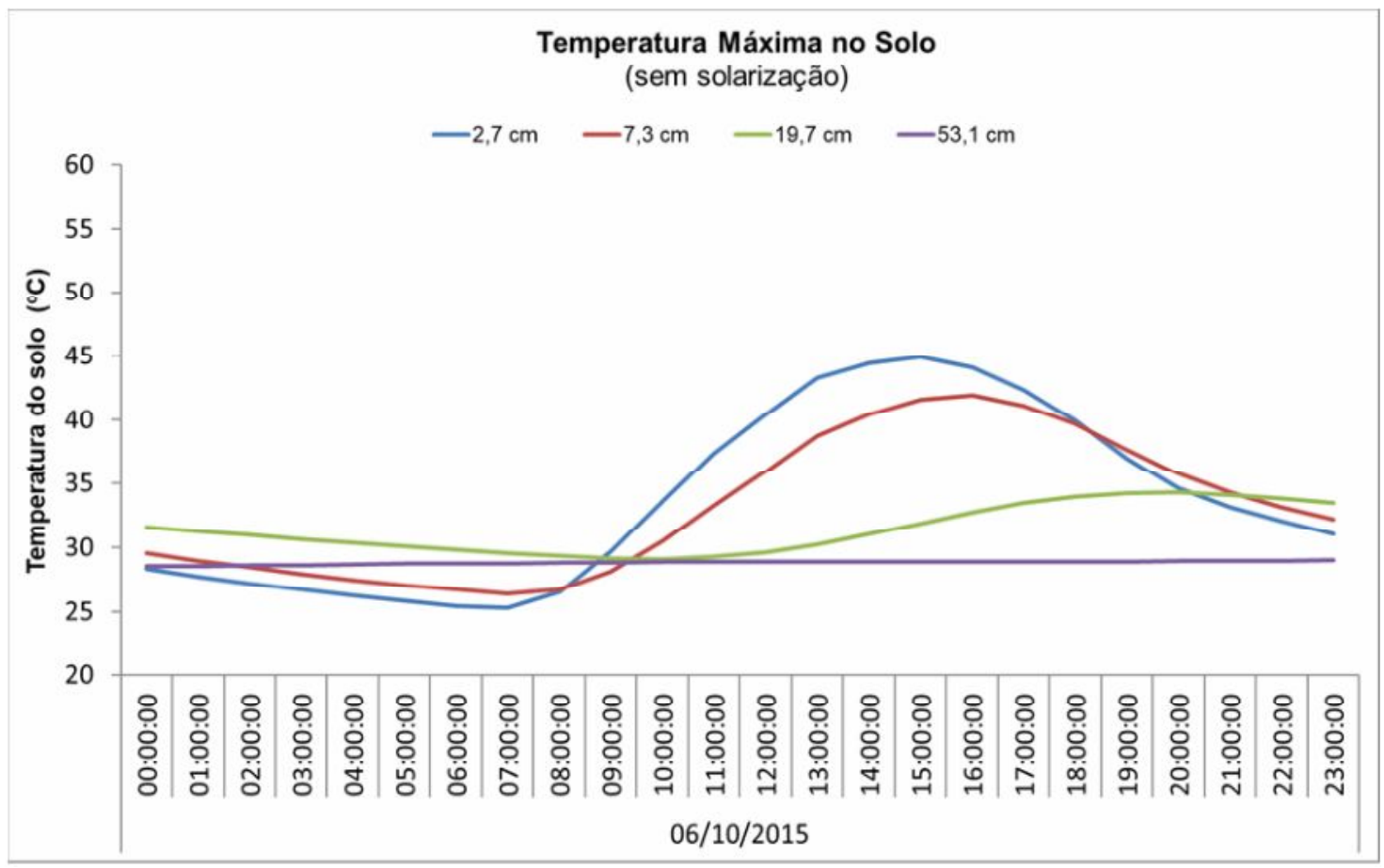

FIGURA 3 - Temperatura média do solo sem solarização no dia 06 de outubro de 2015. 
Tais dados corroboram com Diniz et al. (2014), cujos autores afirmam que temperaturas mais elevadas são verificadas por volta das 15:00 horas, atingindo valores até $40^{\circ} \mathrm{C}$. Carneiro et al. (2013) mensurando a temperatura do solo em profundidades $(1,5,10,20,50 \mathrm{~cm})$ em áreas com e sem cobertura por liteira, relatam que a incidência de radiação solar global favoreceu o aquecimento do solo, em média de $33,5^{\circ} \mathrm{C}$, entre as 12:00 e 15:00 horas na estação seca para ambos tipos de cobertura. Estudos realizados por Dantas et al. (2017), em diferentes profundidades do solo $(5,10,30,50 \mathrm{~cm})$, verificaram alterações horárias e mudanças de temperatura entre as profundidades analisadas, na qual a camada superficial de $5 \mathrm{~cm}$ atingiu temperaturas mais elevadas, para os meses de janeiro e julho em estudo. Com o aumento da profundidade, a temperatura máxima é alcançada mais tardiamente, evidenciando a presença de um fluxo de calor gradativo no solo.

Os dados de temperatura máxima referente ao sistema solarizado durante 0 período de avaliação, são exibidos na Figura 4. As camadas superficiais apresentaram temperaturas de maior magnitude, sendo verificado o ponto mais elevado em torno de 54 e $50^{\circ} \mathrm{C}$, nas profundidades de 2,7 e $7,3 \mathrm{~cm}$. A precipitação ocorrida durante a condução do experimento, nos dias 01 e 03, contribuiu para que houvesse uma queda de temperatura no solo. Nota-se que isso não afetou as camadas mais profundas, que assumiram valores praticamente constantes, demonstrando sofrer pouca influência das variações de temperatura.

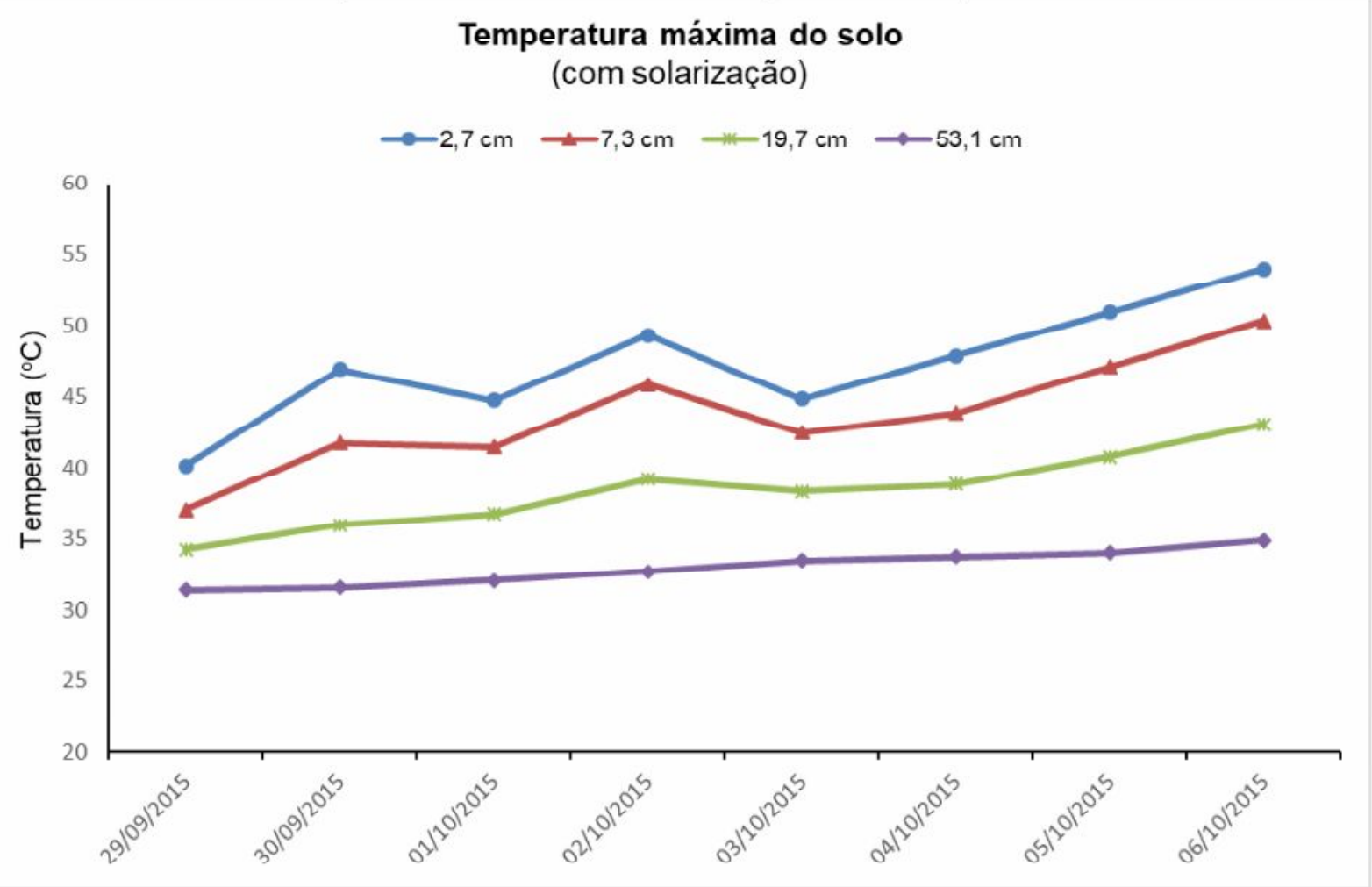

FIGURA 4 - Média da temperatura máxima do solo com o sistema de solarização do solo.

Valores da ordem de $54^{\circ} \mathrm{C}$, foram encontrados por Ribas et al. (2015) entre os meses de outubro a maio, porém com a utilização do polietileno opaco preto. $O$ polietileno transparente apresentou temperaturas de $55,8^{\circ} \mathrm{C}$ e o solo desnudo obteve até $49,2^{\circ} \mathrm{C}$. Barbosa et al. (2014), trabalhando com diferentes coberturas no solo, constataram nos meses de outubro a dezembro que a utilização do filme plástico ENCICLOPÉDIA BIOSFERA, Centro Científico Conhecer - Goiânia, v. 15 n.28; p. 672 
preto, proporcionou maior produtividade, além do aumento de peso médio dos frutos por planta na cultura do pepino do tipo conserva, quando comparado ao solo descoberto.

Quanto ao sistema não solarizado, seus dados de temperatura são demonstrados na figura 5 . Nota-se que temperaturas mais intensas são observadas no sistema solarizado, enquanto que no sistema não solarizado, não foram vistos valores superiores a $45^{\circ} \mathrm{C}$.

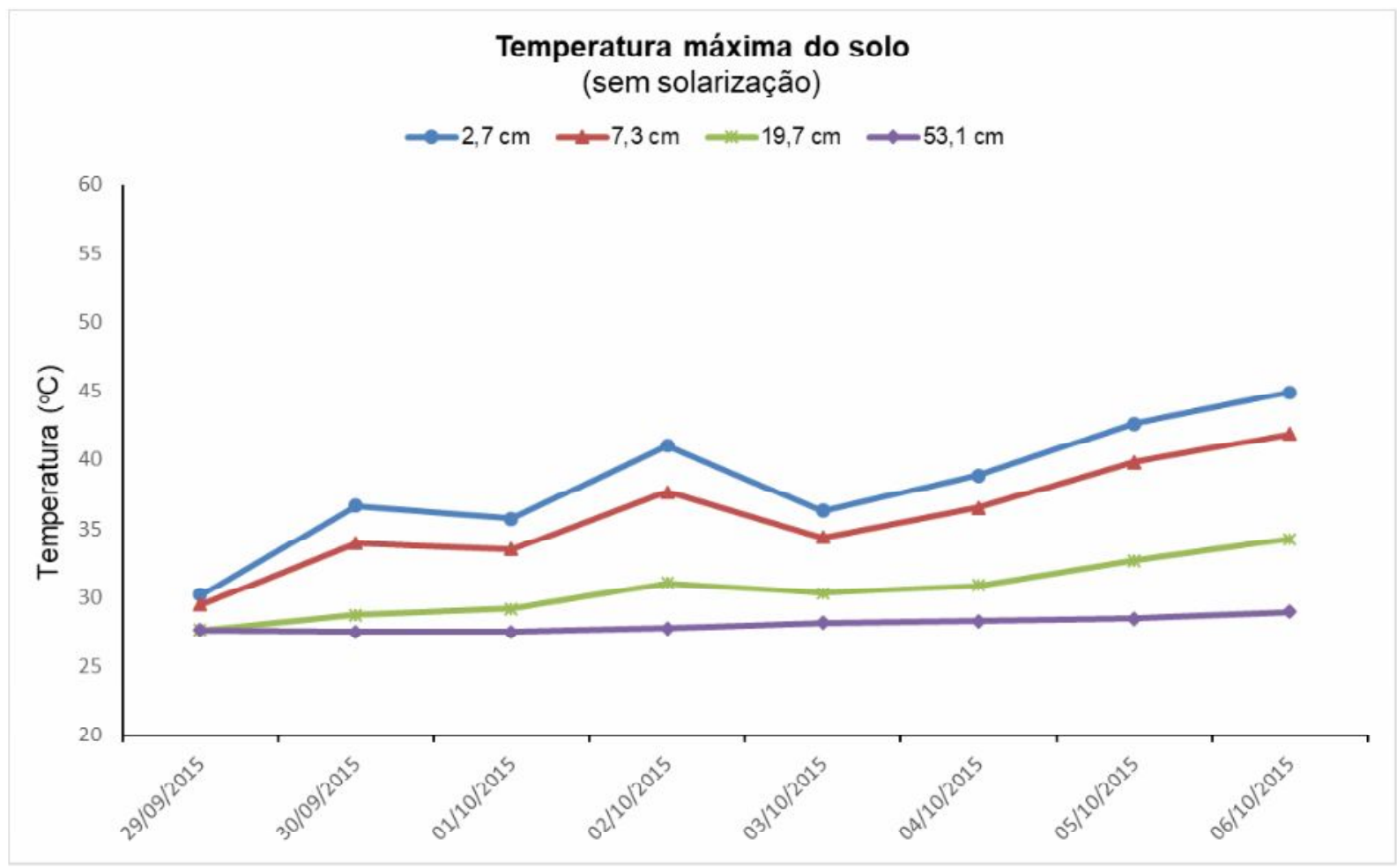

FIGURA 5 - Média da temperatura máxima do solo sem o sistema de solarização do solo.

Conforme verificado por Carneiro et al. (2013) no período seco de novembro a janeiro em que a temperatura do solo apresentou maiores variações nas camadas até $10 \mathrm{~cm}$. Meneses et al. (2016), analisando distintas coberturas do solo durante julho e agosto, identificaram que o emprego do polietileno transparente se destacou por apresentar maiores temperaturas, em relação ao solo com e sem cobertura vegetal.

Pinheiro et al. (2014), mensurando o efeito da temperatura na germinação da cebola em laboratório no decorrer de doze dias, constataram que valores superiores a $30^{\circ} \mathrm{C}$, foram prejudiciais para as cultivares de cebola em estudo. Souza et al. (2013), analisando cultivares de alface americana durante março até junho, verificaram que as temperaturas máximas durante o ensaio variaram entre 25,5 a $36^{\circ} \mathrm{C}$, influenciaram na precocidade de mudas para transplante e consequentemente as cultivares apresentaram redução do ciclo vegetativo, encurtando a época recomendada para colheita de 90 dias para 67 dias.

Segundo Embrapa (2015), o aquecimento resultante da técnica de solarização do solo, durante três a oito semanas, período em que os primeiros 30 $\mathrm{cm}$ de profundidades atingem temperaturas de 35 a $50^{\circ} \mathrm{C}$, reduzem a incidência de plantas daninhas, patógenos de solo, além do controle eficiente de nematoides. 
Ribas et al. (2015), evidenciaram que durante seu experimento, a área com cobertura plástica transparente não houve o crescimento de plantas daninhas.

\section{CONCLUSÃO}

Conclui-se que a temperatura do solo não solarizado apresenta maior amplitude térmica em camadas superficiais e à medida que se aumenta a profundidade do solo a temperatura tende a diminuir. Para solos solarizados, a amplitude térmica é maior nas camadas mais profundas, quando comparado ao sistema sem solarização.

\section{REFERÊNCIAS}

ABOUZIENA, H. F.; HAGGAG, W. M. Weed control in clean agriculture: A review. Revista Planta daninha, v. 34, n. 2, 2016. Disponível em: <http://dx.doi.org/10.1590/S100-83582016340200019>

AIMI, L. Solarização do solo no controle de fitopatógenos. 2013. 24 f. Trabalho de Conclusão de Curso (Especialização) - Universidade Federal de Goiás, Jataí, 2013.

BARROS, B. C.; PATRícIO, F. R. A; LOPES, M. E. B. M.; FREITAS, S. S.; SINIGAGLIA, C. et al. Solarização do solo com filmes plásticos com e sem aditivo estabilizador de luz ultravioleta. Horticultura Brasileira, Brasília, v. 22, n. 2, p.253259, 2004. Disponível em: <http://dx.doi.org/10.1590/S0102-05362004000200018>.

BARBOSA, A. P.; KONDO, P. N. Y.; HORA, R. C.; GOMES, G. R.; FREIRIA, G. H. Desempenho produtivo de pepino tipo conversa sob diferentes coberturas de solo. Enciclopédia Biosfera-Centro Cientifico Conhecer, Goiânia, v. 10, n. 19, p. 751759, 2014. Disponível em: <http://www.conhecer.org. br/enciclop/2014b/ AGRARIAS/desempenho\%20produtivo.pdf>.

CARNEIRO, R. G.; Moura, M. A. L.; Silva, V. P. R.; Junior, R. S. S.; Andrade, A. M. D. et al. Variabilidade de temperatura do solo em função da liteira em fragmento remanescente de mata atlântica. Revista Brasileira de Engenharia Agrícola e Ambiental, Campina Grande, v. 8, n. 1, p. 99-108, 2014. Disponível em: <http://dx.doi.org/10.1590/S1415-43662014000100013>.

DINIZ, J. M. T.; ALBUQUERQUE, E. M.; RAFAEL, R. A. Estudo acerca da variabilidade térmica do solo. Scientia Plena, v. 10, n. 1, p. 1-7, 2014. Disponível em: <https://www.scientiaplena.org.br/sp/article/view/1368/927>.

DANTAS, D.; BARBOSA, G. P.; CUNHA, E. G. S.; SOUZA, M. J. H.; SOUZA, C. M. $P$. Temperatura do ar e do solo em diferentes profundidades, em Diamantina- MG. Caderno de Ciências Agrárias, v. 9, n. 3, p. 61-66, 2017. Disponível em: <https://seer.ufmg.br/index.php/ccaufmg/article/view/9246>.

EMBRAPA. Empresa Brasileira de Pesquisa Agropecuária. Sistema brasileiro de classificação de solos. 2 ed. Rio de Janeiro: Embrapa Solos, 2006. 306 p.

EMBRAPA - Empresa Brasileira de Pesquisa Agropecuária. Manejo de nematoides na cultura da alface. Embrapa Hortaliças: Brasília, 2013. 
EMBRAPA. Empresa Brasileira de Pesquisa Agropecuária. Alternativa para o manejo integrado de nematoides-das-galhas do cafeeiro. Porto Velho: Embrapa Rondônia, 2014.

FACTOR, T. L.; LIMA, J. R. S.; PURQUEIRO, L. F. V.; BRANCO, R. F.; BLAT, S. F. et al. Produtividade e qualidade de tomate em função da cobertura do solo e planta com agrotêxtil. Revista Horticultura Brasileira, v. 27, n. 2, 2009. Disponível em: <http://www.abhorticultura.com.br/eventosx/trabalhos/ev_3/ a1887_t3272_comp.pdf >

FENNER, W.; DALLACORT, R.; SILVA, S. F.; NEVES, S. M. A. S.; BARBIERI, J. D. et al. Zoneamento do índice de satisfação de exigências hídricas para o feijoeiro em Mato Grosso. Revista Brasileira Engenharia Agrícola Ambiental. V, 21, n. 7, 2017. Disponível em: <http://dx.doi.org/10.1590/1807-1929/agriambi. v21n7p476$480>$

KATAN, J., DEVAY, J. E. Soil solarization: historical perspectives, principles, and uses. Soils solarization, Florida, p. 23-37, 1991.

KUVA, M. A.; PEDRO, L. C. A.; ERASMO, E. L. A. Efeitos da solarização do solo através de plástico transparente sobre o desenvolvimento da tiririca (Cyperus rotundus). Revista Planta Daninha, v. 13, n. 1, p. 26-31, 1995. Disponível em: <http://dx.doi.org/10.1590/S0100-83581995000100005>.

MENESES, N. B.; MOREIRA, M. A.; SOUZA, I. M.; BIANCHINI, F. G. Crescimento e produtividade de alface sob diferentes tipos de cobertura do solo. Revista Agro@mbiente on-line, v. 10, n. 2, p. 123-129, 2016. Disponível em: <http://dx.doi.org/10.18227/1982-8470ragro.v10i2.3009>.

PINHEIRO, G. S.; ANGELOTTI, C. V.; SANTANA, C. V.; DANTAS, B. F.; COSTA, N. D. Efeito da temperatura sobre a germinação de sementes de cebola. Scientia Plena, v. 10, n. 11, p. 1-6, 2014. Disponível em: <https://www.scientiaplena.org.br/ sp/article/view/1855/1082>.

PUHL, A. L. Solarização do solo para controle alternativo de plantas daninhas. 2013. 36 p. Trabalho de Conclusão de Curso (Especialização) - Universidade Federal da Fronteira Sul, Cerro Largo, 2013.

RIBAS, G. G.; STRECK, N. A.; SILVA, S. D.; ROCHA, T. S. M.; LANGNER, J. A. Temperatura do solo afetada pela irrigação e por diferentes coberturas. Revista Engenharia Agrícola, v. 35, n. 5, p. 817-828, 2015. Disponível em: <http://dx.doi.org/10.1590/1809-4430-Eng.Agric.v35n5p817-828/2015>

ROCHA, G. A.; CARNEIRO, L. C. Solarização do solo associada à incorporação de material orgânico na redução da viabilidade de escleródios. Revista Ciências Agroambientais, v. $14, \quad$ n. 1 , p. 10-17, 2016. Disponível em: < https://periodicos.unemat.br/index.php/rcaa/article/download/836/1383> 
SANTOS, R. F.; ELENA BLUME, E.; HECKLER, L. I.; MÜLLER, J.; SILVA, G. B. P. et al. Solarização do solo associada à aplicação de Trichoderma spp. no controle de Sclerotinia sclerotiorum. Revista de Ciências Agrarias, v. 57, n. 3, p. 322-325, 2014. Disponível em: < http://dx.doi.org/10.4322/rca.nc1035>

SOUZA, A. L.; SEABRA JUNIOR, S.; DIAMANTE, M. S; SOUZA, L. H. C.; NUNES, M. C. M. Comportamento de cultivares de alface do tipo Americana sob clima tropical. Revista Caatinga, Mossoró, v. 26, n. 4, p. 123-129, 2013. Disponível em: $<$ https://periodicos.ufersa.edu.br/index.php/caatinga/article/view/2829/pdf_79>. 